\title{
Non-contact three-dimensional cell cluster formation on demand in open dishware using focused surface acoustic waves through a couplant layer
}

\author{
Jiyang Mei ${ }^{1}$, Aditya Vasan ${ }^{1}$, Uri Magaram² ${ }^{2}$ Kenjiro Takemura ${ }^{3}$, Sreekanth Chalasani ${ }^{2}$, and \\ James Friend ${ }^{1}$ \\ ${ }^{1}$ University of California San Diego \\ ${ }^{2}$ Salk Institute for Biological Studies \\ ${ }^{3}$ Keio Gijuku Daigaku
}

November 29, 2021

\begin{abstract}
Three-dimensional cell agglomerates are broadly useful in tissue engineering and drug testing. We report a well-free method to form large (1-mm) multicellular clusters using 100-MHz surface acoustic waves (SAW) without direct contact with the media or cells. A fluid couplant is used to transformthe SAW into acoustic streaming in the cell-laden media held in a petri dish. The couplant transmits longitudinal sound waves, forming a Lamb wave in the petri dish that, in turn, produces longitudinal sound in the media. Due to recirculation, human embryonic kidney (HEK293) cells in the dish are carried to the center of the coupling location, forming a cluster in less than $10 \mathrm{~min}$. A few minutes later, these clusters may then be translated and merged to form large agglomerations, and even repeatedly folded to produce a roughly spherical shape of over $1 \mathrm{~mm}$ in diameter for incubation - without damaging the existing intercellular bonds. Calcium ion signaling through these clusters and confocal images of multiprotein junctional complexes suggest a continuous tissue construct: intercellular communication. They may be formed at will, and the method is feasibly useful for formation of numerous agglomerates in a single petri dish.
\end{abstract}

\section{Hosted file}

manuscript_sm.docx available at https://authorea.com/users/448544/articles/547347-noncontact-three-dimensional-cell-cluster-formation-on-demand-in-open-dishware-using-

focused-surface-acoustic-waves-through-a-couplant-layer 